$\begin{array}{ll} & \text { Etnográfica } \\ \text { etnográfica } & \text { Revista do Centro em Rede de Investigação em }\end{array}$

Antropologia

vol. 18 (1) | 2014

Vol. 18 (1)

\title{
A produção das margens do Estado no centro de São Paulo: sem-teto nas ruínas de um presídio abandonado
}

The production of the state margins in São Paulo's central area: homeless in the ruins of an abandoned prison

\section{Edson Miagusko}

\section{(2) OpenEdition}

\section{Journals}

\section{Edição electrónica}

URL: https://journals.openedition.org/etnografica/3329

DOI: 10.4000/etnografica.3329

ISSN: 2182-2891

\section{Editora}

Centro em Rede de Investigação em Antropologia

\section{Edição impressa}

Data de publição: 1 fevereiro 2014

Paginação: 33-52

ISSN: 0873-6561

\section{Refêrencia eletrónica}

Edson Miagusko, «A produção das margens do Estado no centro de São Paulo: sem-teto nas ruínas de um presídio abandonado», Etnográfica [Online], vol. 18 (1) | 2014, posto online no dia 14 março 2014, consultado o 11 fevereiro 2022. URL: http://journals.openedition.org/etnografica/3329 ; DOI: https://doi.org/10.4000/etnografica.3329

\section{(c) (7) \&}

Etnográfica is licensed under a Creative Commons Attribution-NonCommercial 4.0 International License. 


\section{A produção das margens do Estado no centro de São Paulo: sem-teto nas ruínas de um presídio abandonado}

\section{Edson Miagusko}

O artigo segue a trajetória dos sem-teto a partir da ocupação das ruínas de um presídio no centro de São Paulo. Da "invasão" à organização de um movimento de sem-teto, de sua desorganização à inserção do tráfico de drogas, buscamos compreender a produção de ocupações como práticas do Estado nas suas margens. Deste modo, o Estado não apenas cria as ocupações de sem-teto a partir de suas práticas, como também estabelece os graus de tolerância e as fronteiras entre ação política, formas de gestão e criminalização. A construção dessas margens do Estado, do legal e do ilegal, do lícito e do ilícito se dá a partir das práticas desse mesmo Estado dentro dele e nas suas margens, como lugares fundamentais por onde essas definições são estabelecidas e que respondem também à agência dos sem-teto.

PALAVRAS-CHAVE: sem-teto, moradia, áreas centrais, requalificação urbana, Estado, São Paulo.

The production of the state margins in São Paulo's central area: homeless in the ruins of an abandoned prison - The article follows the trajectory of people with no access to housing (sem-teto) beginning with the occupation of the ruins of a prison in São Paulo's central area. From the "invasion" to the organization of a social movement of homeless people, from their disorganization to the insertion of drug dealing, we understand the occupations as practices of the state in its margins. Thus, the state not only creates the occupations by these homeless with its' practices, but it also establishes the degree of tolerance and the boundaries between political action, management methods and criminalization. The construction of these margins of the state, the legal and the illegal, the licit and the illicit, starts from the practice in the state and its margins as key places where these definitions are established and that also respond to the homeless' agency.

KEYWORDS: homeless, housing, center areas, urban reclassification, state, São Paulo.

MIAGUSKO, Edson (emiagusko@ufrrj.br) - Núcleo de Análises em Políticas Públicas, Universidade Federal Rural do Rio de Janeiro (UFRRJ), Brasil. 
A AFIRMAÇÃO COMUM SOBRE AS FORMAS DE AÇÃO POLÍTICA DE movimentos de sem-teto é que são ilegais e, portanto, denominadas como "invasões" pelo Estado e pela mídia. 'Já no discurso dos movimentos de moradia estas ações são motivadas pela ausência de políticas sociais capazes de atender uma demanda empobrecida de moradores da cidade que não conseguem pagar os aluguéis ou acessar as faixas de financiamento habitacional pelos mecanismos formais. Em resposta às ações desencadeadas por movimentos de sem-teto a ação do Estado é apenas reativa, seja reprimindo, seja negociando o atendimento dessas demandas.

Nosso trabalho caminha num sentido oposto desta compreensão, buscando apontar como as relações entre o que se considera ordem e desordem são mais entrelaçadas e produzidas pelas práticas desse mesmo Estado do que comumente se concebe. Tanto a simples classificação de invasão ilegal que cobra do Estado umas ações para coibir essas práticas e restabelecer uma determinada ordem ou a perspectiva de uma ausência do Estado como agente de uma política de habitação impedem a percepção do jogo modulado que resulta das práticas desse Estado em suas margens e como estas são ressignificadas pelas populações que são objeto dessa ação. ${ }^{2}$

Nesse texto buscamos compreender a ação dos sem-teto como produto do Estado na produção de suas margens, ao mesmo tempo em que redefine as próprias tecnologias de poder desse mesmo Estado em resposta a suas ações. Não é apenas a ausência de políticas públicas que leva à ocupação dos imóveis vazios, mas a construção de uma determinada ordem e suas diversas modulações, da legitimação à criminalização da ação dos sem-teto.

Essas diferentes modulações constroem o lugar e as nomeações dos sem-teto e sua definição como público-alvo de políticas governamentais. Isso faz com que num momento uma ocupação de sem-teto seja realizada e até incentivada

1 A primeira versão do texto foi apresentada na 28. ${ }^{a}$ Reunião Brasileira de Antropologia, no grupo de trabalho "Abordagens etnográficas de mercados informais, ilegalismos, comércios ilegais e práticas de controle", coordenado por Lênin Pires e Brígida Reinoldi. Agradeço ao comentador da sessão, José Lindomar Coelho Albuquerque, e aos participantes do grupo pelos comentários e sugestões. E também aos pareceristas anônimos da revista, que sugeriram importantes modificações para a versão final do texto.

2 Essa perspectiva, de uma antropologia das margens, busca analisar o Estado a partir de suas práticas, se distanciando de uma imagem consolidada do Estado como "forma administrativa racional de organização política que se debilita ou não está completamente articulado em suas margens territoriais". Deste modo, essa perspectiva abre uma interessante possibilidade de análise do Estado, não porque registre ou capte formas "exóticas" presentes nas margens, mas porque insinua que as margens são implicações necessárias do Estado e, portanto, não podem ser lidas no registro de conceitos que apresentam as margens como anômicas, caóticas ou desordenadas, e sim como móveis e dinâmicas. O princípio é que aquilo que era aplicável às margens pode generalizar-se e normalizar-se para todas as populações, do mesmo modo que a regra é parte constitutiva da exceção. Essa perspectiva é apresentada de maneira seminal e profícua no livro organizado por Das e Poole (2004), Anthropology in the Margins of the State. 
por agentes do Estado e em outro duramente criminalizada. Estas fronteiras também se alteram conforme a visibilidade da região e os tipos de práticas adotadas pelos agentes do Estado e pelos sem-teto em conjunturas distintas.

A fim de tratar da produção dessas margens tomamos o caso de uma ocupação espontânea nas ruínas de um presídio, cujas obras foram embargadas e que estão situadas no coração do centro industrial da cidade de São Paulo. Esta ocupação, realizada em 1999, é uma das mais longevas da cidade e já passou por todas as fases das políticas urbanas, desde o momento em que o centro passou a figurar como um problema urbano visível a partir do esvaziamento populacional, até sua visibilidade como habitação e espaço de cultura e requalificação urbana. ${ }^{3}$ Esses sentidos continuam ainda em disputa, como demonstram as recentes intervenções da prefeitura num quadrilátero próximo ao bairro da Luz e que foi denominado como "Crackolândia", mesmo que o momento atual seja marcado menos pelas práticas de gestão desse mesmo Estado em relação ao sem-teto e mais por sua criminalização.

Neste sentido, as indicações de Das e Poole (2004) são relevantes para compreender que as práticas estatais não podem ser entendidas em termos de lei e transgressão, mas como práticas simultaneamente dentro e fora da lei. Das e Poole seguem as pistas de Agamben (2004), que afirma que a exceção é parte constitutiva da norma. Deste modo, o Estado não apenas cria as ocupações de sem-teto a partir de suas práticas, como também estabelece os graus de tolerância e as fronteiras entre ação política, formas de gestão e criminalização. Mas isso seria apenas uma apreensão comum da visão do Estado, a partir de sua institucionalidade. A construção dessas margens do Estado, do legal e ilegal, do lícito e do ilícito se dá a partir das práticas desse mesmo Estado em e nas suas margens, como lugares fundamentais por onde essas definições são estabelecidas e que respondem também à agência dos sem-teto em dado momento.

Assim, ao contrário de compreendermos essas margens como desorganizadas, caóticas ou anômicas, propomos perseguir o ordenamento que torna possível a existência de ocupações relativamente precárias nas condições de habitação de seus moradores, na situação jurídica da posse e nas relações internas e externas à ocupação, mas que permanecem como uma dimensão da política de habitação estatal em determinados momentos, ainda que isso crie situações em que a própria existência é constantemente negociada.

É a partir de uma ocupação de sem-teto de um presídio abandonado no centro de São Paulo e da história de uma de suas moradoras que procuraremos compreender as práticas desse Estado nas suas margens. Ao invés de

3 Sobre os processos de requalificação urbana no centro de São Paulo já há uma extensa literatura que trata da temática. Sobre isso, cf. Frúgoli Jr. (2000), Gonçalves (2006), Valadares (2007), Kowarick (2007), Kara José (2007), Frúgoli Jr. e Sklair (2009). 
pensarmos na ausência de uma política pública de atendimento aos moradores nos perguntamos como as políticas da vida nestas zonas "à margem" conformam as práticas sociais que originam as políticas sociais.

A própria documentação e registro dessas populações se tornam possíveis porque homens e mulheres "infames" (Foucault 1992) aparecem e são capturados pelas malhas do poder da assistência social, das políticas de triagem de migrantes, dos albergues e dos programas habitacionais existentes.

Para seguirmos esse percurso nosso artigo se divide em três partes: na primeira contextualizamos o cenário em que ocorrem os processos de renovação urbana e as ocupações de sem-teto na segunda metade dos anos 1990; na segunda parte, buscamos, a partir da história da ocupação e da narrativa de uma de suas moradoras, mostrar como as práticas do Estado delimitam o próprio modo de vida da ocupação, sua legitimidade e criminalização e legibilidade dos indivíduos que estão nessas ocupações, bem como as formas de ação que subjazem numa situação de encolhimento de possibilidades. $\mathrm{Na}$ última parte, retornamos à produção das margens do Estado e organização das categorias predominantes.

\section{PROCESSOS DE RENOVAÇÃO URBANA NO CENTRO DE SÃO PAULO E OCUPAÇÕES DE SEM-TETO NOS ANOS 1990}

$\mathrm{Na}$ última década as políticas urbanas no centro de São Paulo ${ }^{4}$ se ampliaram, a ponto de legitimar políticas dos poderes públicos nos três níveis no delineamento de intervenções urbanas prioritárias, de recursos de financiamento de organismos internacionais, de grande exposição na mídia sobre os "problemas" urbanos da região, de ampliação do escopo de pesquisas e da realização de seminários, conferências e estudos. ${ }^{5}$

No plano dos movimentos de moradia, também aconteceu fenômeno semelhante. A partir da segunda metade da década de 1990, os movimentos de sem-teto deslocaram sua atuação mais visível da periferia da cidade para o centro, ampliando as ações de ocupação de imóveis e edifícios vazios na região. ${ }^{6}$

4 Os treze subdistritos que compõem a região central de São Paulo são: Sé, República, Liberdade, Bela Vista, Consolação, Santa Cecília, Bom Retiro, Belém, Brás, Mooca, Pari, Cambuci e Barra Funda. 5 No âmbito do poder público e de pesquisas que reuniram um conjunto de pesquisadores com o objetivo principal de apresentar propostas de intervenção urbanística para a região central de São Paulo, ver Câmara Municipal de São Paulo (CMSP 2001), Emurb (2004) e Silva (2006). Também há um interesse renovado pela região central, com múltiplos enfoques, em dissertações, teses acadêmicas e artigos nas áreas de arquitetura e urbanismo, geografia, ciência política, sociologia, antropologia, engenharia. Sobre isso, ver Piccini (1998), Kohara (1999), Frúgoli Jr. (2000), Bonfim (2004), Teixeira et al. (2005), Levy (2005), Gonçalves (2006), Valadares (2007), Kara José (2007), Kowarick (2007), Frúgoli Jr. e Sklair (2009).

6 Dados atualizados do Censo de 2010 (IBGE) apontam que no centro de São Paulo há 13\% de imóveis vazios, ou seja, 22.087 unidades. Se comparados aos dados de 2000, há uma reversão [continua] 
Em levantamento realizado na grande imprensa sobre as ocupações protagonizadas por movimentos de moradia e sem-teto em São Paulo entre os anos de 1997 e 2007, foram registradas 112 ocupações de edifícios vazios, imóveis abandonados, ruínas de equipamentos públicos e terrenos, tanto de propriedade privada como pública. Desse total, 83, ou seja, 74,1\% de todas as ocupações aconteceram nos treze distritos da região central. E desse total, a quantidade de prédios ocupados foi bem maior, se comparada às ações dos movimentos de moradia nos anos 1980, que privilegiavam a ocupação de grandes terrenos vazios nas periferias. ${ }^{7}$

Do ponto de vista dos movimentos de moradia, o centro era representado como espaço de riquezas e comércio e sua população pobre era percebida com desconfiança e ceticismo, por ser de difícil organização e associada ao "mau pobre" dos cortiços ou ao morador de rua. O trabalho com esta população era protagonizado pela Igreja Católica no plano da caridade e da filantropia. A visibilidade do centro como local de pobreza adquiriu projeção a partir dos movimentos de sem-teto. O centro como prioridade, espaço visível de intervenção de políticas urbanas, reivindicado pelos movimentos de sem-teto para moradia popular é fenômeno recente.

Por que se altera esta percepção do centro como lugar em que as ações dos movimentos sociais esbarrariam na difícil organização de seus moradores pobres? Por que os movimentos de sem-teto do centro adotaram outra nomeação - "sem-teto" - e novas formas de ação política, como ocupações de edifícios e imóveis vazios, além da gestão das ocupações e políticas sociais que rompem com os patamares anteriores das políticas públicas? Por que essa "vontade de saber" (Foucault 2005: 20-21) leva a região a se tornar um espaço privilegiado de intervenção do poder público, com investimentos vultosos, e também como

do quadro de esvaziamento populacional da região. Entre 1980 e 2000, o centro perdeu cerca de $30 \%$ de sua população, tomados os treze distritos que o compõem. O Censo de 2000 apontava a existência de 420.237 domicílios vazios em São Paulo e, deste total, 10\% ou 45 mil na região central. O distrito da Sé, núcleo principal da região, respondia por mais de um quarto do total vago, com 11.384 imóveis vazios. Esta taxa de desocupação contrasta com a infraestrutura urbana instalada, com as redes de serviços e com a proporção de empregos por habitante. Em termos comparativos, o centro possuía 18\% de imóveis desocupados, enquanto na região metropolitana a desocupação era menor, com $12 \%$ de imóveis vazios. Aliás, a dinâmica de esvaziamento populacional e transferência de serviços para outras regiões foi o mote principal que conferiu visibilidade ao centro como um problema urbano, social e político da cidade. A partir do final dos anos 1990 podemos verificar que o discurso sobre o problema fez com que o centro se tornasse palco de fortes investimentos públicos e de visibilidade midiática.

7 Esses dados foram levantados para minha tese de doutorado, com base em pesquisa nos jornais Folha de São Paulo, O Estado de São Paulo e Diário de São Paulo, e confrontados com informações de integrantes dos movimentos de moradia e sem-teto. É possível que os números sejam ainda maiores, dado o número de ocupações não organizadas por estes movimentos sociais e nem noticiadas pelos órgãos de imprensa. Ainda assim, os dados apontam o deslocamento das ações de movimentos de sem-teto, bem como a visibilidade maior da mídia e da opinião pública para a região central da cidade (Miagusko 2012: 216-220). 
espaço de produção de conhecimento sobre seu território, de vontade de saber de urbanistas, geógrafos e sociólogos? Qual o contexto e a história que levam a esse interesse e deslocamento de olhar sobre a região?

Esse contexto coincide com dois cenários: os processos de "requalificação urbana" que transformam o centro no principal campo de conflitos da cidade no final dos anos 1990; o segundo, o contexto do "desmanche", ${ }^{8}$ que determina o campo e o raio de ação desses movimentos e das políticas sociais que se conformarão para responder a essa demanda. Assim, o centro de São Paulo tornou-se um laboratório avançado das políticas urbanas e dos programas sociais.

Historicamente, a quantidade de investimentos públicos e privados no centro é maior que em qualquer região de São Paulo. Piccini (1998) calcula que em $4,4 \mathrm{~km}^{2}$, área que compreende os distritos da Sé e República, o poder público investiu 25 bilhões de dólares para a instalação de redes de água, luz, esgoto em $2.744 .000 \mathrm{~m}^{2}$ de área construída para fins residenciais e $6.857 .000 \mathrm{~m}^{2}$ para outras finalidades (Piccini 1998: 66).

Segundo pesquisa RAIS, $28,85 \%$ dos empregos formais estão localizados no centro, distribuídos em 49.676 estabelecimentos, média superior ao restante do município. Enquanto em São Paulo há 16 empregos/hectare, no centro esse número salta para 137 (Ministério do Trabalho 2000). Oitenta mil empregos formais nos setores de serviço e comércio estão sediados no centro.

Apesar da transferência das sedes de bancos e investimentos financeiros para a região da Avenida Paulista e, posteriormente, para o eixo da Avenida Berrini, atividades financeiras e de crédito pessoal, reciclagem de cheques pré-datados e corretoras de valores (as sedes da Bovespa e a Bolsa de Mercadorias e Futuros estão no centro), cooperativas de crédito, empresas de previdência privada e seguro de saúde cresceram em número de estabelecimentos e na quantidade de empregos.

Esses números destacam a dinâmica urbana, em que redes de transporte, serviços, empregos, infraestrutura urbana e investimentos públicos, empregos, equipamentos culturais e educacionais, repartições públicas e empresas de ramos econômicos diversos passam pela região. E apontam uma reversão da dinâmica de esvaziamento populacional verificada até meados dos anos 1990.

8 O termo "desmanche" foi cunhado por Schwarz (1993) como uma imagem figurada dos processos em curso no Brasil nos anos 1990 e que significaram o desmonte do aparelho produtivo estatal, a desnacionalização da economia, a desregulação dos direitos sociais, privatizações do sistema produtivo estatal, etc. O "desmanche" remetia a uma análise daquilo que estava se reconfigurando, não apenas no sentido do desmonte do Estado, mas também ao desmonte de um horizonte de instituições e estruturas pelas quais era possível fazer um tipo de experiência social. Tomado em perspectiva, o desmanche foi um conceito inspirador que ressaltava a ideia de uma mudança da cena pública ou, pelo menos, de uma mutação significativa no contexto que demandava diretamente a alteração das próprias categorias de análise. 
Por outro lado, também podemos perscrutar nos números uma população que se esconde das estatísticas, de difícil contagem e nomeação (Barros 2004). Assim, diante da precisão das demais quantidades, os números dessa pobreza são mais difíceis de contabilizar, tornarem-se visíveis e conferir sentidos para as políticas públicas voltadas para a assistência e atendimento dessa população. Aqui, as duas dimensões da criminalização e da gestão de populações muitas vezes visibilizam para esconder o problema efetivo. Ainda assim, é possível levantar alguns números para ressaltar a pobreza do centro e o convívio com uma demanda em situações de maior vulnerabilidade.

Em função da oferta de empregos e das possibilidades de sobrevivência, das redes de atendimento público e privado, da quantidade de serviços disponíveis, da proximidade com o trabalho, há um atrativo para residência da população mais pobre frente às condições precárias de habitação, permanência e violência. Em São Paulo há 57.670 moradores em cortiços em 1502 edificações, dez mil ambulantes, dois mil catadores de papel/papelão e materiais recicláveis e 10.394 moradores de rua. É possível dizer, pelas características dessas populações, que a maioria habita o centro.

Esse movimento não passou despercebido e no final dos anos 1990 a região passou a ser "visibilizada", tanto pelos discursos proferidos, de pesquisas acadêmicas, da mídia, como, sobretudo, pelas intervenções do poder público (nos três níveis), de associações empresariais e também dos movimentos sociais. Podemos situar a visibilidade da região como um "problema" ou uma "questão urbana" a partir do momento em que apareceram discursos que ressaltavam o esvaziamento populacional, a suposta perda do dinamismo econômico, o "empobrecimento" da região e seu abandono.

O debate em torno do "esvaziamento populacional" foi tomado, de outro lado, pelos movimentos de sem-teto, cujo marco de surgimento é a metade final dos anos 1990. E o discurso é o da possibilidade de habitação popular no centro. Assim, se constrói a proposta de políticas habitacionais como elemento de disputa pelos movimentos de sem-teto, ressaltando a diversidade da ocupação na região, ou seja, um espaço urbano de múltiplas funções que pudesse combinar empregos, serviços e também moradia.

Há uma verdadeira polêmica sobre quem poderia e deveria morar no centro. De um lado, associações empresariais e setores que se congregavam em torno da Associação Viva o Centro, que compreendiam que o centro não comportaria habitação para as camadas de menor renda, em razão da dificuldade de essas populações poderem arcar com o elevado custo da moradia e dos serviços. E de outro, os movimentos de moradia e sem-teto e redes acadêmicas que defendiam o maior adensamento da região, fixando uma população mais pobre, em razão da oferta de serviços, dos equipamentos públicos, da infraestrutura urbana consolidada e do grande número de imóveis vazios que poderiam ser reformados e convertidos em habitação popular. 
Esta disputa percorreu todo o período recente. Ora a tentativa de construir políticas denominadas como de "interesse social" se apresentava como possibilidade para a população de baixa renda, a partir de programas que buscavam atender famílias que recebiam até três salários mínimos, ${ }^{9}$ ora se reforçavam políticas de "revitalização" e "gentrificação" que buscavam expulsar essa população mais pobre, descartando do ponto de vista do poder público qualquer tipo de política ou programa habitacional no centro em escala mais ampliada. Nos anos posteriores ao momento em que fizemos a pesquisa de campo que deu origem ao artigo, o segundo tipo de política foi predominante e afetou profundamente as ações dos movimentos de sem-teto no centro.

Em relação aos movimentos de sem-teto, também houve uma reconfiguração na demanda que participava de suas ações. Até meados dos anos 1990, a maior parte dos movimentos por habitação se denominavam movimentos de moradia. A partir dos anos 1990, a visibilidade desses movimentos sociais se deslocou para a região central, o que fez com que aqueles que surgiram nesse momento passassem a se denominar como "movimentos de sem-teto". Além da nomeação definida pela ausência de um direito - sem-teto -, o perfil de seus integrantes se alterou se comparado àqueles dos movimentos de moradia dos anos 1980. Da demanda anterior de populações com empregos precários, que buscavam sair do aluguel e podiam "esperar na fila" de um programa habitacional, como no caso dos mutirões em São Paulo (Miagusko 2011), os movimentos de sem-teto passavam a organizar também a população de rua, moradores de baixos de viaduto e de outras ocupações na cidade, não apenas para reivindicar programas habitacionais, mas para habitarem o próprio imóvel abandonado. A diferença aparentemente sutil tem sua maior evidência na alteração da nomeação desses movimentos, nas suas formas de organização e no próprio repertório político.

Do ponto de vista do Estado, as ações passaram a ser focadas nessa população mais vulnerável, através do maior controle sobre sua presença na cidade ou a partir de diferentes políticas públicas que a tomavam como "público-alvo".

Assim, a política habitacional que existia como horizonte de direitos na cidade e mesmo como reivindicação dos movimentos de moradia foi sendo substituída cada vez mais por programas. E estes programas acabaram se tornando mais políticas de assistência às populações mais vulneráveis, tornando cada vez mais indistinta a diferença entre política de direitos e programas de gestão da pobreza.

A trajetória de Beatriz, uma moradora dessas ocupações, nos permite observar como as práticas do Estado nas suas margens não podem ser compreendidas a partir de uma legalidade e sua transgressão, mas como práticas simultaneamente dentro e fora da lei. Assim, o Estado cria muitas vezes as 
ocupações de sem-teto e estabelece graus de tolerância também em resposta à agência dos sem-teto, do mesmo modo que estes se movimentam numa cena que é conformada por estas mesmas práticas. Através da trajetória de Beatriz podemos perscrutar esse tipo de ação e é dentro de uma dessas ocupações que buscaremos investigar essas práticas.

\section{AS RUÍNAS DO PRESÍDIO E A FORTALEZA DE BEATRIZ NAS MALHAS DO ESTADO}

Nascida em Betim, Minas Gerais, Beatriz tem 37 anos e é a mais nova de quatro filhos. Negra, baixa, olhos grandes e vivos, compleição física forte, braços "musculosos" como faz questão de ressaltar, à primeira vista aparenta ser mais jovem por seu dinamismo, fala rápida e gestos decididos.

A chegada de Beatriz a São Paulo foi aleatória. Queria sair de Belo Horizonte porque "enjoara" de lá, motivo que, no decorrer da conversa, se revela como silenciamento sobre a sucessão de violências expostas na família. ${ }^{10}$ Seu primeiro dia na cidade merece uma descrição mais detalhada, pela aleatoriedade e imprevisibilidade de uma vida marcada pela precariedade e pelo encolhimento de possibilidades.

Antes de chegar a São Paulo, Beatriz abriu o mapa do Brasil e passou em revista as principais capitais. $\mathrm{Na}$ escolha do destino final considerou algumas cidades: Salvador, na Bahia, era só "festa" e, portanto, não haveria trabalho; o Rio de Janeiro, local da "matança", segundo notícias veiculadas na televisão em 1993 e, assim, um lugar violento; Curitiba, capital do Paraná, era "pequena". Finalmente, pousou os olhos em São Paulo, lugar onde não possuía nenhuma rede de parentes ou amigos, mas que lhe pareceu melhor. Tomada a decisão, comprou a passagem e veio "com a cara e a coragem".

Beatriz, no entanto, já sabia que ao chegar encontraria uma agente do Estado, representada por uma assistente social responsável pela triagem dos possíveis migrantes. Assim, inventou justificativa para o caso de ser interpelada e obrigada a retornar: a espera na rodoviária por uma prima inexistente. Seria a primeira das inúmeras instituições estatais de assistência e controle que cruzariam os caminhos de Beatriz no suceder de poucos dias e que depois a iriam acompanhar em outros momentos de sua vida na cidade.

A dramaticidade da chegada a São Paulo contrasta com o modo banal como relembra os fatos. Chegou ao Terminal Rodoviário Bresser às cinco horas da manhã sem previsão do que fazer e ficou esperando o acaso. A gari que varria

10 Ao final da entrevista, Beatriz admite que a saída de Belo Horizonte não decorria do "enjoo" com a cidade. A razão principal era abandonar a vida de privações, a relação difícil com a família, "sanguessugas" que a exploravam se aproveitando de sua orfandade. Abandonar Belo Horizonte era largar a antiga vida de exploração familiar. 
as ruas estranhou o comportamento e começou a conversar com ela. Da conversa, almoçaram um marmitex pago por Beatriz. A prima não chegava e Beatriz continuava na rua. Em certo momento, Beatriz entrou num templo da Igreja Universal e rezou: "Deus me ilumine para eu não ir para a rua". Às cinco da tarde encontrou novamente a gari, que perguntou pela prima, que não chegara. A senhora ofereceu a casa, em Guaianases, ${ }^{11}$ onde morava com a filha e dois netos, em troca dos afazeres domésticos e dos cuidados com o recém-nascido. Beatriz aceitou, o que a levou a escapar de uma possível deportação da cidade na sua chegada, mas que a fez cair em outra das instituições do Estado.

Foi morar com a senhora desconhecida, que a acolheu na chegada a São Paulo. Com ela ficou três meses, até que um mal-estar súbito a levou ao posto de saúde e à revelação da sua gravidez do filho mais velho. Percebeu a mudança de atitude daquela que lhe oferecera amparo. A mulher, parteira, insistiu que não fizesse exames pré-natais. Beatriz desconfiou da "bondade estranha" e conversas com vizinhas a fizeram suspeitar que a benfeitora fosse "traficante de bebês". Fugiu mais uma vez e, sem alternativas, foi para a Central de Triagem e Encaminhamento de Migrantes (Cetrem), albergue para migrantes no Brás. A assistente social levantou seus dados e entrou em contato com a família para enviá-la para Minas, já com a passagem nas mãos e a afirmação de que em São Paulo, ainda mais grávida, ela não teria futuro.

“- Você sabe que aqui não tem futuro, né? São Paulo não tem futuro. Mulher sozinha, ainda mais grávida, com filho, não tem futuro.

Ela foi muito grossa comigo. Eu falei:

- Como não tem futuro, eu tenho duas pernas, dois braços, eu não posso trabalhar?

Ela:

- Não, você é uma pessoa desamparada, eu liguei pra casa da sua tia, sua tia tá que nem uma louca te procurando, você morava com a sua tia, você trabalhava numa firma muito boa lá em Belo Horizonte. [...]

Fez, ela fez tudinho, aqueles cinco dias que eu fiquei lá dentro, ela pegou e foi levantando, ela sabia tudo. Ela falou:

- Eu tô com o dinheiro aqui certinho, eu tô com a passagem pra você voltar pra sua tia, sua tia tá te esperando.

Eu falei:

- Eu não vou. [...]

Ela falou:

- Eu vou chamar a polícia, vou te levar junto com a assistente social e com o pessoal da segurança.

Eu falei: 
- Eu não quero, eu não sou obrigada, eu não sou de menor, eu sou de maior, eu sei o que eu quero da minha vida" [Beatriz, 17/02/2008].

A insistência de Beatriz fez com que a assistente social a colocasse diante de duas possibilidades: ou retornaria a Belo Horizonte ou seria internada no Amparo Maternal ${ }^{12}$ e trabalharia até que a criança nascesse. Ao final teria que assinar um documento para doar o filho. "Lá é assim, tem norma pra tudo". Do hospital só poderia sair com o bebê registrado e uma família que fosse buscá-la.

Beatriz aceitou as condições. Mas, até o dia do parto preocupou-se em evitar a doação do filho. A rotina no hospital das "mães desamparadas" era acordar às cinco da manhã e trabalhar num caldeirão e na máquina de lavagem e secagem de cobertores, puxando e estendendo grossas mantas em cilindros quentes e grandes. A parceira de trabalho, de dezessete anos e grávida de sete meses, sofreria um acidente:

"Era direto, você não parava um minuto. A menina coitada, tava com seis pra sete meses, foi assim, umas máquinas bem grandonas lá do hospital, cê tem que pegar o cobertor e pôr na máquina. Aí a máquina vem e puxa e vai secando o cobertor. Era assim, a gente trabalha direto, pra poder comer lá e morar de graça, tem que fazer alguma coisa. Aí essa menina foi - não gosto nem de lembrar -, ela pegou, acho que ela passou mal, deu uma tonteira, queda de pressão. Ela ficava de um lado, eu ficava do outro, ela pegou e, sei lá, distraiu e a mão dela foi... na máquina” [Beatriz, 17/02/2008].

Depois do acidente, Beatriz "ficou traumatizada" e redobrou os cuidados. A parceira acidentada fez o parto às pressas e, depois do nascimento, o bebê foi encaminhado para a doação. Assim, Beatriz trabalhou dobrado e no dia do parto segurou as contrações até não aguentar as dores. A preocupação era que o filho nascesse de parto normal para não precisar ir para a incubadora e ser recebido no colo no mesmo dia.

No dia seguinte a assistente social foi visitá-la. Além das felicitações, foi verificar a casa da psicóloga que oferecera um trabalho para Beatriz como babá do filho, também recém-nascido. A assistente social temeu que Beatriz doasse o filho para a patroa, ao invés de seguir as regras de primazia da doação para o hospital.

A trajetória de Beatriz parece marcada com frequência pelo enredamento nas malhas dos aparatos estatais de assistência social e controle de fluxos da

12 O Amparo Maternal é uma maternidade filantrópica mantida pela Igreja Católica. Em 2002 foram realizados 14.987 partos, com média mensal de 1.200 crianças, o que significa $7,2 \%$ de todos os nascimentos da Grande São Paulo. Nas palavras da própria instituição, o alojamento social em que Beatriz ficou albergada atende mulheres "carentes, migrantes, sofredoras de rua e também psicopatas, deficientes físicas, drogadas, etc.” A capacidade da maternidade é o atendimento de até cem gestantes por dia. Cerca de 50.000 já foram amparadas pela instituição (ver <http://www.amparomaternal.org >). 
cidade responsáveis pela "triagem" e controle da população mais pobre. Desde o início de sua chegada, Beatriz encontra uma assistente social que procura convencê-la a fazer o caminho inverso, de retorno para uma família que estabelece relações violentas e, portanto, indizíveis por Beatriz. A mesma personagem, somente mudando o nome, atravessa seu caminho no Centro de Triagem e Encaminhamento de Migrantes (Cetrem), no Amparo Maternal, nos albergues da prefeitura e na filantropia religiosa, trabalho no qual Beatriz irá se tornar funcionária por 13 anos.

A regularidade nessa trajetória é a rede de instituições estatais que vão buscar definir o lugar de Beatriz na cidade. Desde o início, estas instituições vão buscar demover Beatriz da possibilidade de ter um lugar e, portanto, poder existir e ser contada na cidade. De outro lado, Beatriz vai buscar se relacionar no interior das práticas desse Estado, nas suas margens, no sentido de favorecer-se de sua situação, buscando escapar de sua viração diária e de sua situação de ampla vulnerabilidade. Uma das práticas de Beatriz para driblar a imprevisibilidade desse mundo encolhido é através da moradia. Isso a leva a comprar um espaço nas ruínas de um presídio cujas obras foram embargadas e a entrar simultaneamente num movimento de moradia para construir seu apartamento num mutirão na região leste de São Paulo.

\section{O "INVADIDO" OU PRESÍDIO-OCUPAÇÃO}

Beatriz mora com dois filhos e o companheiro nas ruínas de uma estrutura de concreto de quatro pavimentos pertencente à Secretaria de Segurança Pública do Governo do Estado e cercada por uma favela de alvenaria. Na área de $8548 \mathrm{~m}^{2}$ moram 750 pessoas, com 305 crianças e adolescentes. Esses números são instáveis e registram um momento de relativa estabilidade em que as ameaças de reintegração da posse do terreno por parte do Estado estavam suspensas, algo que não acontece no atual momento, pelo início de uma operação urbana no corredor industrial em que se localiza o terreno.

O antigo proprietário, o Instituto do Café do Estado de São Paulo (ICESP), repassou a área à Secretaria de Segurança Pública em 1996. A ocupação ocorreu no mesmo ano, quando foram construídos os primeiros barracos. Há um desencontro de informações, mas se sabe que as primeiras famílias vieram desalojadas de outra ocupação de sem-teto, estimuladas por um policial que lhes recomendou a ocupação de áreas públicas no lugar de privadas, pela demora na reintegração de posse por parte dos aparatos estatais. Naquele momento, nas primeiras ocupações de imóveis vazios, havia uma relativa tolerância do poder público, até como uma forma de diminuir as pressões em relação aos programas habitacionais pela população mais pobre.

Na área, a Secretaria de Segurança Pública pretendia construir um novo presídio da Polícia Civil, devido à superlotação do antigo, situado no bairro 
do Carandiru. ${ }^{13}$ Destaca-se a estrutura de concreto de um prédio dividido pelos moradores. Nas paredes externas da estrutura de concreto, há janelas de esquadrias e portas de madeira. No último andar, as paredes são de madeira. Do lado direito, não há paredes e apenas um pequeno muro é aproveitado pelos moradores para secar as roupas. $\mathrm{Na}$ frente, há um pequeno comércio que serve aos moradores e aos operários das fábricas e armazéns próximos. À esquerda, barracos de alvenaria com telhas de zinco e nos fundos uma pequena viela e quarenta barracos encostados à linha do trem.

A Avenida Presidente Roosevelt atravessa o eixo sudeste de São Paulo, correndo paralela à linha férrea Santos-Jundiaí e à Avenida do Estado, começando no bairro da Mooca e se estendendo até os limites do ABC paulista. No passado, a linha do trem dividia o bairro da Mooca: o lado industrial e popular próximo do centro e o lado do comércio e da classe média baixa na parte de cima do bairro. A linha férrea era conhecida como "muro da vergonha", por cindir a Mooca em duas partes. Há quase uma década foi erguido um viaduto que restabeleceu a ligação entre os dois lados da Rua da Mooca. O sentimento no bairro é ambíguo. De um lado, o viaduto permite cortar caminho e escapar do trânsito em direção às regiões nobres do bairro. Por outro lado, para os moradores da Mooca o viaduto religou o lado popular das indústrias, cortiços, moradias deterioradas, ocupações, o que sempre foi um incômodo para os moradores do lado de cima da linha do trem. O "invadido" se localiza na parte de baixo do bairro.

O "invadido", o presídio-ocupação que Beatriz habita, é marcado por uma aceleração do tempo em que os moldes não se deixam fixar. $\mathrm{O}$ molde prisão não chegou a cumprir seu uso inicial e se transformou na modulação ocupação; foi modulado por seus moradores como moradia e, para muitos, com a finalidade de se separar dos riscos em uma fortaleza intransponível, retornando mais uma vez ao esforço para estabelecer um molde que proteja. ${ }^{14}$

13 Não há uma informação precisa sobre o objetivo inicial das obras e a finalidade da estrutura de concreto e não foi possível consegui-la do Governo do Estado. A área da Avenida Roosevelt possui alguns galpões vazios de propriedade dos órgãos públicos ou de privados. Os relatos dos sem-teto dizem que a obra foi embargada pelos vizinhos em função de a instalação de um presídio provocar uma desvalorização automática das outras propriedades. Além do relato dos sem-teto, contamos com duas matérias na grande imprensa e na imprensa alternativa. Uma notícia do Jornal da Tarde, em 13/02/2006, criticava a Secretaria de Segurança Pública que deixava invadir suas áreas, mesmo sendo responsável pela reintegração de posse de outros terrenos, o que indica uma relação do Estado com as ocupações à época distinta da atual. Também afirmava que o destino da área era a construção de um novo presídio para a Polícia Civil, dada a superlotação do atual no Carandiru (Campos 2006). Em notícia veiculada no site do Centro de Mídia Independente (CMI) se expôs a notificação extrajudicial emitida pelo gabinete do Secretário da Segurança Pública, informando que o imóvel foi vendido em 1996 pelo Instituto do Café, uma autarquia estadual, para a Fazenda e é utilizado pela Secretaria como "Divisão de Transportes". 14 Deleuze se refere aos "moldes" e "modulação" quando expõe a passagem das sociedades disciplinares do período que vai do século XVIII até à II Guerra Mundial para as sociedades do controle, que se desenvolvem na segunda metade do século XX. A partir de Foucault, Deleuze observa [continua] 
O presídio foi modulado como uma ocupação pelos "invasores", depois se transformou em modulação do movimento de sem-teto, que levantou um muro a separar os dois lados do presídio para distinguir os bons dos maus pobres. Esta classificação foi adotada pelo movimento de sem-teto, que organizou uma das partes da ocupação antes da chegada de Beatriz.

Naquele momento, havia um conflito entre as lideranças dos sem-teto e os "noias". Numa primeira fase, isso se traduzia na visão dos sem-teto, que apontavam as famílias que habitavam um dos lados da ocupação como "acomodadas", que "não gostavam de trabalhar" e se conformavam em viver na situação precária, sem lutar por seus direitos. O conflito num determinado momento se aguçou e levou à solução de dividir os dois lados da ocupação por um muro que separava as famílias lideradas pelo movimento de sem-teto das demais famílias, do outro lado da ocupação.

As classificações adotadas por Beatriz para se distanciar dos maus pobres da ocupação se referem em primeiro lugar a estabelecer relações polidas, mas sem nenhum contato ou conversa com os chamados "noias". Estes vizinhos ficam no segundo andar da ocupação e na "biqueira" que pode ser avistada de sua casa. A preocupação maior é com seus filhos adolescentes, o que a leva a pagar "perua" para transportá-los até a escola e a orientá-los a nunca sair de casa quando ela não está presente. Isso reforça o verdadeiro mundo de eletroeletrônicos, brinquedos e guloseimas que ela tem no apartamento, como para tornar autossuficiente o atendimento das necessidades dos filhos dentro do apartamento. Os outros de quem ela não quer aproximação são os vizinhos "acomodados", que não trabalham, e as fofoqueiras que comentam sobre a vida alheia. Essa seletividade de Beatriz em relação à vizinhança faz com que ela seja vista como alguém de "nariz empinado", segundo sua própria definição, pelas outras vizinhas.

Por fim, a ocupação foi transformada em fortaleza por Beatriz, na tentativa de separar não apenas simbolicamente, mas fisicamente, a sua moradia do entorno. ${ }^{15}$ Do molde presídio ao molde ocupação e depois ao molde fortaleza,

[continuação] no confinamento a operação par excellence das sociedades disciplinares, em espaços delimitados, ordenados pelo tempo industrial (prisões, escolas, indústrias, mosteiros, etc.). Esses processos são denominados por ele como de "moldagem", pois um mesmo molde fixo e definido pode servir às mais diversas formas. Haveria uma passagem dos confinamentos, moldes das sociedades disciplinares, para os controles, modulações das sociedades do controle, "como uma moldagem autodeformante que mudasse continuamente, a cada instante, ou como uma peneira cujas malhas mudassem de um ponto a outro" (Deleuze 2000: 221).

15 Beatriz não chega a utilizar o termo fortaleza para descrever o apartamento que construiu dentro do "invadido". Mas é possível utilizar a palavra para descrever esse movimento de Beatriz, que, ao morar num lugar "precário" e com uma vizinhança "complicada", busca construir um espaço de separação e eliminação de possíveis contatos dela e de seus filhos com os vizinhos indesejáveis. 
a trajetória dessa ocupação acompanha todas as fases das políticas de Estado e dos seus aparatos para as populações mais vulneráveis do centro de São Paulo.

O "invadido" ou presídio-ocupação é um molde do confinamento, desmanchado antes mesmo de ser utilizado e transformado numa ocupação que organiza, em meio a situações liminares, vidas marcadas por uma privatização radical e pelo encolhimento de possibilidades, mas paradoxalmente se tornou uma das ocupações mais perenes do centro de São Paulo.

\section{A FORTALEZA DE BEATRIZ}

O apartamento é o principal investimento de Beatriz. A chegada ao "invadido" aconteceu por indicação da colega de trabalho e estímulo da diretora da creche em que trabalhou. O apartamento tem sete cômodos: sala de televisão, sala de jantar, cozinha, dois banheiros e dois quartos. O quarto que divide com o companheiro é a lavanderia, banheiro do casal e o ponto de água do tanque de roupa.

Antes da ocupação, Beatriz morava numa casa de quarto e cozinha em Heliópolis e com o trabalho na creche pagava o aluguel que pesava no orçamento. Foi nesse período que ingressou no mutirão e resolveu fazer um curso supletivo noturno para concluir o primeiro grau. Nos dias de estudo economizava no transporte e andava a pé com o filho pequeno.

Diante do esforço, uma colega de trabalho que comprara um terreno na ocupação aconselhou Beatriz a fazer o mesmo. Era uma opção para sair do aluguel, mas Beatriz hesita em tomar a decisão e relata o conselho da patroa:

“- A Elma [a amiga] comprou um terreno.

Eu falei:

- Comprou um terreno?

- Por que você não faz igual?

- Eu? Comprar um terreno?

— É, ela pagou duzentos reais.

Eu falei:

- Que mentira! Como que existe isso?

Ela:

— É lá no invadido.

Eu falei:

— Ah, é, dona Clara, só que morar no invadido, ou você morre, ou você sai escorraçado pela polícia.

Ela:

- Não. Lá tem muita família, tenta pra você ver.

Aí eu falei:

— Mas será que vai dar certo? 
- Vai.

- Mas se eu morar lá a senhora não vai poder me escorraçar da creche porque eu vou tá morando com sem-teto?

Aí ela:

- Não tem nada a ver, cê vai tá morando e economizando seu dinheiro.

Aí eu fui, não gostei dali. Tinha um outro ali que era da polícia, um galpão muito pobre, muito pobre" [Beatriz, 17/02/2008].

Apesar de afirmar que o outro galpão era da “polícia”, Beatriz não sabia que a futura moradia também era uma área da Secretaria de Segurança Pública e as fundações das obras de um presídio. Conversando com uma amiga, Beatriz descobre o "invadido". Resolve visitar a ocupação e, depois de pensar, escolhe o espaço da lajem no terceiro andar, combina com o "proprietário", fecha "negócio" e compra a vaga por mil reais. Dá como parcela de entrada uma televisão e paga o restante em cinco prestações ao antigo vizinho, dono de mais alguns "lotes", obrigado a sair em função de problemas com o tráfico. Mesmo após a saída dele, ela depositava o dinheiro na conta do "proprietário".

Nos cálculos de Beatriz, a escolha do andar mais alto evitava a proximidade da futura moradia com a vizinhança, o que poderia render sérios problemas com a polícia, pois transformaria o apartamento em local de passagem do tráfico e em rota de perseguição em caso de complicações com a polícia. ${ }^{16}$ Mas, acima de tudo, buscava fazer com que Beatriz se diferenciasse dos vizinhos "acomodados" e tornaria transitório o projeto de morar na ocupação precária.

A "regra" estabelecida só permitia a "compra e venda" e era proibido para um mesmo "proprietário" alugar o local para outros. Afinal, "só mora lá quem precisa" e os "noias" 17 não autorizavam alguém a ganhar dinheiro com a necessidade alheia:

"Não, os noia, os noia não gosta, cê tá querendo ganhar, você mora aqui porque precisa, comprou o terreno aqui porque não tem dinheiro. Aí cê vem aqui e fica, que nem eu, eu moro nesse espação, todo mundo sabe que eu moro nesse espação, sabe que mora só eu, meus filhos e meu marido. Vai eu

16 Este projeto de vida por um fio não parece se encerrar na trajetória somente de Beatriz. Cavalcanti (2007), ao tratar de uma moradora de uma favela carioca, também mostra como estes projetos estão sempre por um fio. A referida moradora também buscou construir uma fortaleza que a diferenciasse dos demais moradores, à medida que melhorava de vida, conforme a estabilização da situação familiar. Contudo, o ingresso do filho de uma vizinha nas redes de tráfico tornou o corredor da sua casa, comum a outros moradores, em possível rota de fuga e perseguição de policiais, o que a obrigou a deixar a passagem livre para o vizinho incômodo. Com essa alteração, a referida moradora viu seu projeto de ascensão individual vir abaixo.

17 O termo "noia" aqui não significa apenas a nomeação pejorativa do consumidor de crack, mas nomeia também o "zelador anônimo" que controla o pequeno comércio de drogas do local e impõe as regras de convivência para os demais moradores. 
pegar, ficar alugando, dividindo, pra ver se eles não botam pra correr. Eles é esperto, não é bobo não, eles não tão nem aí que eu moro nesse espaço enorme, nem aí, ninguém vem tomar. Mas se eu vim dar uma de espertona aqui, meu mutirão tá pra sair, se eu sair eu tenho que ir embora daqui. Eu tenho que desocupar pra quem precisa, não dá pra ficar morando nos dois lugares. Então, alugar aqui e morar lá em Itaquera, ${ }^{18}$ eles acabam descobrindo e botam pra correr" [Beatriz, 17/02/2008].

Com o decorrer do tempo, levantou as paredes e fechou o apartamento. Depois ergueu as paredes que separam os cômodos e em seguida colocou a grade no corredor. Quando Beatriz chegou, não existiam paredes, o que resultou na queda do filho de uma vizinha do terceiro andar. O episódio trágico lhe apressara o investimento para levantar o muro externo e Beatriz cercou as passagens e entradas tornando o ambiente escuro. $\mathrm{O}$ espaço interno possui duas portas de madeira que separam o apartamento do corredor, com duas chaves tetra, além das correntes e do cadeado. Os fios das lâmpadas visíveis e entremeados nas ligações elétricas fazem funcionar os eletrodomésticos da casa e as poucas lâmpadas do ambiente. A falta de água é o principal inconveniente de morar no último andar da estrutura de concreto, pois seu corte constante nos horários de maior uso faz com que os trabalhos domésticos devam ser realizados de madrugada, horário em que a água chega aos pavimentos superiores.

As melhorias transformaram gradativamente o apartamento de Beatriz numa fortaleza e cada parede é parte da história de sacrifícios de seu projeto de moradia na ocupação. Mas o apartamento é a concretização do "projeto provisório" que chegou ao limite. O apartamento agora está todo cercado e separado do "invadido".

Os corredores e áreas comuns do prédio têm avisos que soam como ameaça e apontam a existência de um "zelador anônimo" atento às pequenas faltas. Uma mensagem escrita na escada liga o primeiro ao segundo andar do prédio e ilustra a advertência: "Furtar as lâmpadas é traição. Nós lhe pegaremos."

Os dois meninos não convivem com a vizinhança, pois a mãe prefere afastá-los do ambiente. Assim, o apartamento é autossuficiente, com duas geladeiras, fogão, máquina de lavar roupa, três televisões, videocassete, DVD e aparelho de som. Alguns eletrodomésticos estão na prestação do carnê, pago religiosamente, e outros serão abertos quando terminar o mutirão. O carrinho, comprado em prestações do camelô e que corre a toda velocidade de um lado a outro do apartamento, batendo nos móveis e nos nossos pés, é o mais recente presente para os filhos. As crianças brincam e após um tempo já enjoam, procurando outra diversão. 
Beatriz me convida para me aproximar da janela e observar a vista panorâmica que dá para toda a região central da cidade, de onde podemos avistar a Avenida do Estado, o Parque Dom Pedro e a catedral da Sé. Na viela abaixo, dois jovens estão entediados debaixo de um grande guarda-sol, aguardando a aproximação de clientes em motos, carros ou a pé. O movimento é fraco. Crianças correm e brincam de pega-pega. Adultos apressados entram e saem. Um homem chega de motocicleta, cumprimenta todos, ergue a camisa e é saudado. Apesar de ser domingo, próximo ao horário do almoço, o funcionamento é normal. A portaria principal está fechada para carros e donas de casa correm para preparar o almoço. A movimentação é calma e o ritmo é de domingo ensolarado. Trata-se de uma "biqueira" que funciona na rua paralela à ocupação.

\section{PRODUÇÃO DAS MARGENS DO ESTADO}

\section{A PARTIR DE UMA OCUPAÇÃO DE SEM-TETO}

As ocupações dos sem-teto resultam das práticas do Estado nas suas margens. Não é apenas a ausência de políticas públicas que leva às ocupações dos imóveis vazios, mas a construção de uma determinada ordem e suas diversas modulações que legitimam ou criminalizam essas ações. A ação do Estado nas suas margens produz situações que o seu aparato diz combater. Assim, um deslocamento das políticas de Estado redefine constantemente as fronteiras e os problemas a serem enfrentados não como polaridades, mas como margens móveis e dinâmicas a depender das práticas e da gestão desses dispositivos.

Um segundo conjunto de questões diz respeito às tecnologias de poder específicas para tornar legíveis essas populações. Beatriz depara a todo o momento com aparatos estatais de assistência social e controle de fluxos da cidade que a tratam como objeto de políticas públicas relacionadas às populações vulneráveis ou fora do horizonte de moradora da cidade, pressionando-a para retornar para sua cidade anterior. A situação de Beatriz é exemplar dessa relação com os diversos aparatos do Estado, do controle dos fluxos, triagem, assistência social às políticas habitacionais. Beatriz mostra como é entre os mais pobres que a presença do Estado como forma de controle é significativa. Os lugares de moradia de Beatriz acompanham os fluxos e deslocamento das políticas governamentais e de assistência que deslocam os pobres e também são utilizados como forma de escapar de uma vida marcada pela precariedade e pelo encolhimento de possibilidades.

Por fim, o texto procurou demonstrar, a partir de uma ocupação que se tornou uma das mais duradouras do centro de São Paulo, como as práticas dos sem-teto são ressignificadas pelos mesmos que são objeto das práticas do Estado. É o caso do "invadido", onde o presídio foi modulado como uma ocupação pelos "invasores", e depois se transformou em modulação do movimento de sem-teto, que levantou um muro a separar os dois lados do presídio 
para distinguir os bons dos maus pobres. Buscámos mostrar a modulação da ocupação se transformando numa fortaleza por uma de suas moradoras, na tentativa de separar não apenas simbolicamente, mas também fisicamente, a sua moradia do entorno. Do molde presídio ao molde ocupação e depois ao molde fortaleza, a trajetória dessa ocupação acompanhou todas as fases das políticas de Estado e dos seus aparatos para as populações mais vulneráveis do centro de São Paulo.

\section{BIBLIOGRAFIA}

AGAMBEN, Giorgio, 2004, Estado de Exceção. São Paulo, Boitempo.

BARROS, Joana da Silva, 2004, "Moradores de rua - pobreza e trabalho: interrogações sobre a exceção e a experiência política brasileira”. São Paulo, Faculdade de Filosofia, Letras e Ciências Humanas de Universidade de São Paulo, dissertação de mestrado em Sociologia.

BONFIM, Valéria Cusinato, 2004, "Os espaços edificados vazios na área central da cidade de São Paulo e a dinâmica urbana”. São Paulo, Escola Politécnica da Universidade de São Paulo, dissertação de mestrado em Engenharia.

CMSP - CÂMARA MUNICIPAL DE SÃO PAULO, 2001, Comissão de Estudos sobre Habitação na Área Central. São Paulo, CMSP.

CAMPOS, M., 2006, "Polícia deixa invadir e agora quer tomar de volta", Jornal da Tarde, 13 de fevereiro.

CAVALCANTI, Mariana, 2007, "Do barraco à casa: tempo, espaço e valor(es) em uma favela carioca”, Anais do 31. Encontro Anual da Associação Nacional de Pós-Graduação e Pesquisa em Ciências Sociais (Anpocs), vol. 1. Caxambu, Anpocs.

DAS, Veena, e Deborah POOLE (orgs.), 2004, Anthropology in the Margins of the State. Santa Fé (NM)/Oxford (UK), School of American Research Press/James Currey.

DELEUZE, Gilles, 2000, "Post-scriptum sobre as sociedades de controle", em Gilles Deleuze, Conversações. São Paulo, Editora 34, 219-226.

Emurb - Empresa Municipal de Obras e Urbanização, 2004, Caminhos para o Centro: Estratégias de Desenvolvimento para a Região Central de São Paulo. São Paulo, Emurb/Cebrap (Centro Brasileiro de Análise e Planejamento).

FOUCAUlT, Michel, 1992, “O que é um autor?", em Michel Foucault, A Vida dos Homens Infames. Lisboa, Passagens, 89-128.

FOUCAUlT, Michel, 2005, El Orden del Discurso. Buenos Aires, Fabula Tusquets Editores.

FRÚGOli JR., Heitor, 2000, Centralidade em São Paulo: Trajetórias, Conflitos e Negociações na Metrópole. São Paulo, Cortez/Edusp.

FRÚGOLI JR., Heitor, e Jéssica SKLAIR, 2009, "O bairro da Luz em São Paulo: questões antropológicas sobre o fenômeno da gentrification”, Cuadernos de Antropología Social, 30: 119-136. 
GONÇALVES, Jean Pires de Azevedo, 2006, "Ocupar e resistir: problemas de habitação no centro pós-moderno (SP)”. São Paulo, Faculdade de Filosofia, Letras e Ciências Humanas de Universidade de São Paulo, dissertação de mestrado em Geografia.

KARA jOSÉ, Beatriz, 2007, Políticas Culturais e Negócios Urbanos: A Instrumentalização da Cultura na Revitalização do Centro de São Paulo (1975-2000). São Paulo, Annablume/Fundação de Amparo à Pesquisa do Estado e São Paulo (Fapesp).

KOHARA, Luís T., 1999, "Rendimentos obtidos na locação e sublocação de cortiços: estudos de caso na área central da cidade de São Paulo”. São Paulo, Escola Politécnica da Universidade de São Paulo, dissertação de mestrado em Engenharia.

KOWARICK, Lúcio, 2007, “Áreas centrais de São Paulo: dinamismo econômico, pobreza e políticas”. Lua Nova, 70: 171-211.

LEVY, Charmain, 2005, "The housing movement in the city of São Paulo: crisis and revival", em Michel Duquete e Charmain Levy (orgs.), Collective Action and Radicalism in Brazil: Women, Urban Housing and Rural Movements. Toronto, University of Toronto Press.

MIAGUSKO, Edson, 201 1, "Mutirão autogestionário e o contexto da experiência democrática revisitado", Cadernos do CRH, 24 (61): 167-181.

MiaguSKo, Edson, 2012, Movimentos de Moradia e Sem-Teto em São Paulo: Experiências no Contexto do Desmanche. São Paulo, Alameda Editorial/Fundação de Amparo à Pesquisa do Estado e São Paulo (Fapesp).

MINISTÉRIO DO TRABALHO, 2000, "Registros administrativos da Relação Anual de Informação Social: Brasília, Série 1990 a 2000”, disponível em <www.mte.gov.br>.

PICCINI, Andreia, 1998, Cortiços na Cidade: Conceito e Preconceito na Reestruturação Urbana de São Paulo. São Paulo, Annablume.

SCHWARZ, Roberto, 1993, Seqüências Brasileiras. São Paulo, Companhia das Letras.

SILVA, Helena Menna Barreto, 2006, Relatório de Pesquisa: Observatório do Uso do Solo e da Gestão Fundiária do Centro de São Paulo. São Paulo, Lincoln Institute/Labhab (Laboratório de Habitação e Assentamentos Humanos).

TeIXeIrA, A.C.C., et al., 2005, Estudo de Caso: Conflitos em torno do Direito à Moradia na Região Central de São Paulo. São Paulo, Polis/Ibase (Instituto Brasileiro de Análises Sociais e Econômicas).

VALADARES, Kleber W., 2007, "O problema da habitação no contexto de revalorização do centro histórico de São Paulo (1991-2006)”. São Paulo, Faculdade de Filosofia, Letras e Ciências Humanas de Universidade de São Paulo, dissertação de mestrado em Geografia. 